\title{
A decision support system-based procedure for evaluation and monitoring of protected areas sustainability for the Mediterranean region
}

\author{
K Pediaditi ${ }^{1,2, *}$, F Buono ${ }^{3}$, F Pompigna ${ }^{4}$, C Bogliotti ${ }^{3}$,

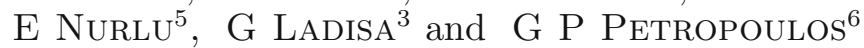 \\ ${ }^{1}$ Department of Environmental Management, Mediterranean Agronomic Institute of Chania, \\ Alsylion Agrokepion, Chania, P.O. Box 185, 73100, Crete, Greece. \\ ${ }^{2}$ Ministry of Environment, Energy and Climate Change, 17 Amaliados Str., 11523 Athens, Greece. \\ ${ }^{3}$ Mediterranean Agronomic Institute of Bari, 70010 Valenzano, Bari, Italy. \\ ${ }^{4}$ Department of Biological and Environmental Science and Technologies, \\ University of Salento - Ecotkne, 73100 Lecce, Italy. \\ ${ }^{5}$ Department of Landscape Architecture, Faculty of Agriculture, Ege University, 35100 Izmir, Turkey. \\ ${ }^{6}$ Department of Earth Sciences, University of Bristol, Queens Road, Bristol, BS8 1RJ, United Kingdom. \\ *Corresponding author.e-mail: kalliapediaditi@hotmail.com \\ fabrizia.buono@gmail.com; fpompigna@alice.it; bogliotti@iamb.it; \\ engine.nurlu@ege.edu.tr; ladisa@iamb.it; george.petropoulos@bristol.ac.uk
}

Despite common acknowledgement of the value of protected areas as instruments in ensuring sustainability, and their promotion for the achievement of policies on halting the loss of biodiversity, there is no common approach today for monitoring and evaluating them. This paper presents a novel integrated nature conservation management procedure developed to monitor and evaluate the sustainability of Mediterranean protected areas. This procedure was successfully implemented and formally evaluated by protected area managers in six Mediterranean countries, results of which are presented here together with an overview of the web-based Decision Support System (DSS) developed to facilitate its wide adoption. The DSS and procedure has been designed and evaluated by managers as a useful tool, which facilitates and provides needed procedural guidance for protected area monitoring whilst minimizing input requirements to do so. The procedure and DSS were developed following a review of existing protected area assessment tools and a detailed primary investigation of the needs and capacity of its intended users. Essentially, the procedure and DSS guides provide the facilities for protected area managers, in following a participatory approach to develop a context-specific sustainability monitoring strategy, for their protected area. Consequently, the procedure is, by design, participatory, context specific, holistic and relevant to protected area management and institutional procedures. The procedure was piloted and formally evaluated in Greece, Italy, Turkey, Egypt, Malta and Cyprus. Feedback collected from the pilot evaluations is also summarised herein.

\section{Introduction}

The Mediterranean region is characterized as "one of the most original bio-geographical regions in the world ..., but also one of the most threatened" (Benoit and Comeau 2005, p. 9). In the UNEP Protocol concerning areas specially protected for biological diversity, Mediterranean countries have

Keywords. Assessment; management, participation; indicators; decision support systems, protected area management. 
pledged to "protect, preserve and manage in a sustainable and environmentally sound way areas of particular natural or cultural value via the establishment of specially protected areas" and to identify and monitor the effects of activities which are likely to have an impact on the conservation and sustainable use of biological diversity (Art 3, p. 10 UNEP 1996). For the purpose of this paper, a protected area (PA) is defined as "an area of land and/or sea especially dedicated to the protection and maintenance of biological diversity, and of natural and associated cultural resources, and managed through legal or other effective means" (IUCN 1994, p. 7), and evaluation is defined as "the systematic determination of the quality or value of something" (Scriven 1991). Furthermore, Thorsell (1982) defines evaluation, in a PA management context, as the process of making reasonable judgments about programme effort, effectiveness, efficiency and adequacy with the objective of using these judgments to improve the effectiveness of management.

Monitoring and evaluation invariably make use of indicators; where an indicator is a measure that can be used to illustrate and communicate complex phenomena simply (including trends and progress) over time (Davidson 2005). An array of sustainability indicators 'tools', 'toolkits', and 'checklists' have been developed to measure sustainability at different levels (ISSD 2005). A review of the literature and of over 40 evaluation tools carried out for this study (available on world database of protected areas - http://www.wdpa.org/), confirmed the lack of a common framework to monitor and evaluate the sustainability of PA management reported by Hockings (2003). The lack of a common framework justifies the lack of systematic monitoring and evaluation practice (Bertzky and StollKleemann 2009). Bladt et al (2009), and Delbaere (2006), both underline the need for a common approach to monitoring which crosses different geopolitical boundaries and can inform decision making at different scales. Moreover, Sutherland et al $(2004,2006)$ caution that the continued failure to evaluate will lead to a dogma of uncritically examined conservation practices that can be problematic.

The monitoring and evaluation of PAs is sanctioned through legislation (e.g., Habitats Directive), International conventions (e.g., Ramsar Convention, Convention on Biodiversity), NGOs and institutions such as the WWF, IUCN and UNEP. To this end, a range of monitoring and evaluation processes or recommendations are available (Hockings 2003). However, they do not explicitly address PA sustainability (at the site level) or specifically the Mediterranean region. Their limited meta-evaluation, dissemination and use by decision makers and practitioners is, partly, attributable to a design that does not have user needs, in this case PA managers, in mind (Patton 1997; Sutherland et al 2006; Gross 2006).

A common procedure for the Mediterranean is required because, although conservation action typically takes place at the country level, patterns of biodiversity and ecological processes do not conform to political boundaries (Olson and Dinerstein 1998). This is challenging as the Mediterranean region is characterized for its north-south divide regarding quality of life, development priorities, institutional and governance structures, habitats and species diversity (Benoit and Comeau 2005). This poses a fundamental barrier to the development, adoption and implementation of a common procedure.

Herein, a Protected Area Sustainability Evaluation and Monitoring (PASEM) procedure for the Mediterranean is described. First the rationale for the PASEM design is presented. Secondly, experiences and feedback from the pilot trials are included, establishing the wider applicability of the tool in different countries and PA. The paper concludes with a discussion regarding the scope and future steps required for wider implementation of the developed platform PASEM.

\section{Research design and pilot studies}

The activities, tools and procedure described here, were developed and piloted under the Project INNOVA (code no. A.1.222, available at: http://www.innovaproject.net/typo3/) 'establishing common models of integrated sustainable monitoring, planning and management of high environmental value areas to control natural resources degradation' in the frame of the INTERREG III B Programme 'Archimed' funded by the European Regional Development Fund.

In order to develop the PASEM, a programme of workshops was devised involving stakeholders from seven Mediterranean countries (Greece, Italy, Turkey, Egypt, Malta, Cyprus, Palestine). Twenty stakeholders, involved and experienced in PA management and policy and programme development, attended the first workshop to establish the specifications the PASEM procedure, based on their practical knowledge of PA management resource, skills and time restrictions. The initial PASEM was communicated back to the stakeholders and was refined in further workshops. In addition, to avoid reinventing the wheel, a structured review, using the established Bellagio principles for sustainability monitoring (Hardi and Zdan 1997) of existing PA monitoring and evaluation initiatives was 
Table 1. Characteristics of PASEM procedure pilot areas. Detailed description of pilot protected area PASEM procedure implementation results are available in www.innovaproject.net.

\begin{tabular}{|c|c|c|c|}
\hline Protected area name/location & IUCN category & Designations & Size (ha) \\
\hline Cyprus: Arakapas, Dierona, Kalo Chorio & $\mathrm{V}$ & Area of exceptional natural beauty & 370 \\
\hline Greece: Lefka Ori National Park & III & $\begin{array}{c}\text { Biogenetic Reserve, Man and Biosphere } \\
\text { reserve, NATURA } 200 \text { GR004300614 }\end{array}$ & 52300 \\
\hline Egypt: Omayed Natural Reserve & $\mathrm{V}$ & Man and biosphere reserve & 70.5 \\
\hline $\begin{array}{l}\text { Italy: Palude del Conte e Duna Costiera } \\
\text { di Porto Cesareo }\end{array}$ & IV & NATURA 2000 IT9150028 & 893.3 \\
\hline Malta: Ghadira & IV & NATURA 2000 MT0000015 & 0.3 \\
\hline Turkey: Igneada Longos Forest & II & National Park & 3155 \\
\hline
\end{tabular}

carried out prior to the workshop, ensuring the theoretical robustness of the PASEM procedure.

Pilot trials of the PASEM were carried out in six protected areas (table 1). Following each procedural step, feedback was obtained through ex-ante interviews of participants including evaluation questionnaires of workshops. In addition, nonparticipant observers were utilized to evaluate the ability of participants to carry out workshop exercises. The pilot PAs varied purposefully according to habitat, socio-economic situation, management regime, political and governance influences (table 1), enabling the evaluation of the PASEM procedures wider applicability.

\section{The PASEM procedure's specifications}

Based on the inputs obtained from stakeholders from seven Mediterranean countries and the Bellagio principles (Hardi and Zdan 1997), the PASEM procedure has been designed to be:

- context specific - relevant to specific PA values, threats and management priorities,

- practical - relevant to existing management and governance procedures,

- holistic - evaluate environmental, social, governance and economic dimensions, and

- participatory - promote inclusive access to PA decision making processes, information and education on sustainability monitoring.

\subsection{Context specific}

A context specific approach to PA evaluation and monitoring is one which takes into account the local conditions, values, threats, and management constraints of the PA when designing the monitoring strategy or determining evaluation criteria (Hockings et al 2004). The need for a context specific approach is emphasized in the Directive 92/43/EEC which states that management plans must be 'appropriate and specifically designed for the sites'. Thus, monitoring and evaluating PA needs to be context specific with sustainability indicators that are appropriate for informing PA decision making at the site level, based upon input of local decision makers.

Workshop participants commented that many commonly adopted indicators (e.g., reporting requirements for Habitats Directive) are not relevant to, and do not inform, on the sustainability of on-site management operations. Stakeholders concluded that a process to define context and site specific sustainability indicators was required. However, they also mentioned that 'PA managers are not sustainability or indicator experts' who often focus on aspects of environmental management, detrimental of socio-cultural or economic values. Therefore, indicative lists of environmental socio-cultural and economic values (table 2) and threats relevant to the Mediterranean region (table 3) were formulated and reviewed within the workshops. Review is allowed for explicit consideration of future stakeholders using the PASEM procedure (see section 4).

\subsection{Practical - relevant to management and governance procedures}

The lack of use of existing sustainability indicator tools is increasingly acknowledged in the literature and is attributed, in part, to their lack of integration with existing institutional decision making processes which have the power to influence PA or site sustainability (e.g., Mitchell 1996; Rotheroo et al 1997; Rydin et al 2003). Yet, at a generic level, PA management is a continuous process, consisting of three main components (Thomas and Middleton 2003, p. 23):

- preparation of a management plan;

- implementation of the plan; and,

- evaluation and review of the plan and monitoring of impacts.

The PASEM procedure integrates all the above three components. However, PA management and decision making processes vary between countries 
Table 2. Generic Mediterranean protected area values (adapted from Ervin 2003; Hockings et al 2006).

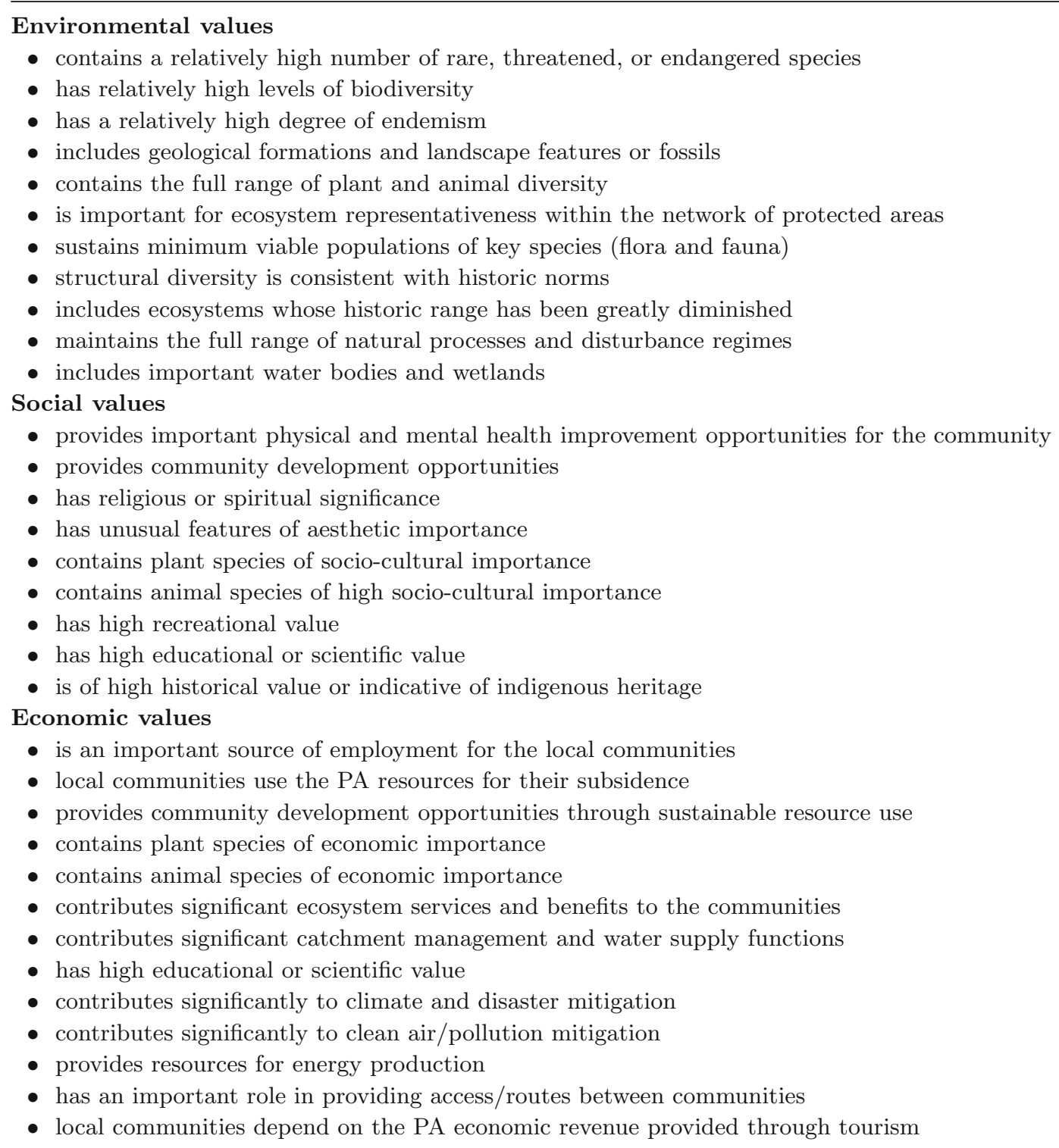

and PA, and structured decision making processes often do not exist. This indicated that the PASEM should include a component of investigation prior to its implementation at any given PA to identify the decision making procedures in place, as well as a degree of flexibility in its application. Additionally, it is imperative that the indicators and monitoring procedures proposed are compatible with the format stipulated in legislation (see for example Article 6 Directive 92/43/EEC and OJ L107, 24.4.1997, p. 1). For non-European member Mediterranean countries where the above Directive does not apply, research should be carried out to determine whether there are any country specific monitoring protocols.

The need to limit resources and bureaucracy of the PASEM was emphasized by PA managers. Budgets of PAs are typically constrained. They may be insufficient to carry out various everyday operations such as - as mentioned during the workshops - waste removal or the hiring of staff. The lack of a monitoring and evaluation budget, is a common phenomenon; it is necessary to reduce cost and allocate a monitoring budget at the onset of a program or project (Posavac and Carey 2007; Stufflebeam and Shinkfield 2007). PASEM aims to address this through a multi-tiered design and a web-based decision support system (see section 4). The need for such a web-based DSS was formally acknowledged in 2008 through the communication 'Towards a Shared Environmental Information System for Europe (COM (2008) 46 final)'.

Most importantly workshop stakeholders commented on the need to recognise available skills and knowhow as well as professional background of PA managers. They commented on a widening 
Table 3. Generic Mediterranean protected area threats (adapted from Ervin 2003; Hockings et al 2006).

Transportation/energy infrastructure threats
Utility lines
Roads
Railroads
Wind farms
Other/non-specified

Abiotic resource use threats

Mining

Oil and gas drilling

Geothermal energy

Water withdrawal

Other/non-specified

Consumptive biological resource use threats

Hunting

Non-timber forest products collection

Grazing

Logging

Plant material cutting (e.g., Reed cutting)

Other/non-specified

Invasive species (alien and native) threats

Plants

Animals

Disease and pathogens

Other/non-specified

Habitat conversion threats

Housing

Industrial development

Farms

Plantations

Tourism infrastructure development

Dams

Other/non-specified

Non-consumptive biological resource use threats

Vehicles

Hiking/biking

Scientific research

Military maneuvers

Other/non-specified

Pollution threats

Acid rain

Solid and liquid waste

Toxins

Radio active fallout

Human caused nutrient imbalance (e.g., fertilizer use)

Other/non-specified

Modification of natural processes/ecological

drivers/disturbance regimes

Climate change

Loss of key predators

Grazing patterns

Fire regime

Fragmentation

Land degradation

Other/non-specified gap between the scientific development of indicators, which are increasingly technical, require use of software that is not widely available at present and training (e.g., in GIS). A common way forward was agreed in the establishment of an open web PA indicator database, where new indicators could be added as well as, comments on experiences of their application. Language barriers were also raised, resulting in the translation of the PASEM procedure in Greek, Arabic, Turkish and Italian.

\subsection{Holistic}

To conduct an evaluation you must define what you are evaluating. Bogliotti (2006) and Hardi and Zdan (1997) state that sustainability evaluation requires the adoption of a holistic approach, giving equal consideration to environmental, social, governance and economic dimensions. PA management sustainability evaluation in this sense is an outcome-based evaluation which requires the definition of PA sustainability priority objectives against which the evaluation can take place (Shalock 2001). Thus, the PASEM procedure was developed with an indicative list of PA management sustainability objectives (table 4) that can be prioritized and refined by users (see section 4). The objectives are generic to all Mediterranean protected areas and have been divided equally to ensure a balanced and holistic consideration of all three sustainability dimensions.

\subsection{Participatory}

In line with the Aahrus Convention on access to information, public participation in decision making and access to justice in environmental matters as well as subsequent EU policy development and legislation stipulating the need for participation in PA management, the PASEM adopts a participatory approach. Moreover, Ukaga (2001) asserts that sustainability indicators should be designed to provide the information which people want to know in order to promote sustainability in their area of interest. Thus, the PASEM procedure adopted a participatory approach which allows its users to define sustainability and relevant indicators themselves.

Adopting a participatory approach is different to technocentric top-down methods adopted by many existing sustainability evaluation and indicator tools (Bell and Morse 2003). Recognition of the necessity of the participatory approach (Mangui and Austen 2008) renders the sustainability objectives as a common starting point for PA stakeholders to determine their objectives and indicators in a way that reflects the specific PA. 
Table 4. Generic Mediterranean protected area sustainability objectives (adapted from Ervin 2003; Hockings et al 2006).

\section{Social objectives}

- To provide opportunities for physical and mental health improvement

- To provide a safe environment for people to work and live in

- To ensure that shelter needs of the local people are maintained

- To provide good access to all

- To provide education opportunities

- To provide appropriate recreation opportunities

- To maintain or restore cultural and heritage values

Economic objectives

- To enable localities to be efficient and competitive

- To provide employment opportunities

- To promote the local economy

- To provide effective infrastructure to meet protected areas needs

- To support local income generation diversity

- To ensure that at a minimum local population subsistence is achieved

- To provide adequate services to serve the local area

Environmental objectives

- To protect biodiversity

- To minimise the use of resources

- To minimise pollution

- To protect the physical function of the landscape

- To protect the aesthetic, scientific value of the environment

- To promote sustainable land use

- To ensure effective waste management

Governance objectives

- To ensure the development and effective implementation of protected area management plans

- To ensure the implementation of holistic risk assessment and environmental management processes (e.g., EIA, SEA, EMS)

- To promote public participation in protected area management and decision making

- To ensure consideration and compliance of protected areas with legislation and policies

- To ensure institutional and financial provision availability for protected area management

- To ensure the provision of transparent information on protected areas to all stakeholders

- To ensure protected area sustainability monitoring and information dissemination mechanisms are in place

Finally, the PASEM can be viewed as a procedure through which new knowledge and ideas on sustainability can enter the decision making process, in a transparent and structured manner, with emphasis placed more on the process of indicator development and assessment than on the indicators themselves. Pilot trial participant and observer feedback underlined the issue that current experience in engagement and facilitation methods should not be taken for granted, they vary between countries and PA. Thus, the detailed guidance on participation and stakeholder analysis, developed in aid of the PASEM, was considered as an essential contribution.

\section{The PASEM procedure Web-DSS: INNOVA platform}

In this section, a description of the PASEM procedure and feedback from its implementation in six countries is presented with the aim of providing readers with sufficient information on the procedure, resources and tools available, that they could adopt PASEM and develop a sustainability monitoring strategy for any PA in the Mediterranean region.

The PASEM procedure consists of a two tiered approach (figure 1) with increasing depth and understanding, time and money input, and knowledge requirement at the second tier. PASEM utilises a web-based DSS named INNOVA platform (see Pace and Di Terlizzi 2008, for a description of DSS architecture). INNOVA platform contains all the guidance documents and the material required to carry out the procedure (e.g., questionnaires in four different languages), and an application that remotely analyses the results, generating a draft PA-specific sustainability indicators list and a PA management effectiveness report (section 4.2). Tier 1 consists of a rapid appraisal, to be conducted by the PA manager. Its main output is an automatically generated report including the evaluation score of the management effectiveness of the PA 

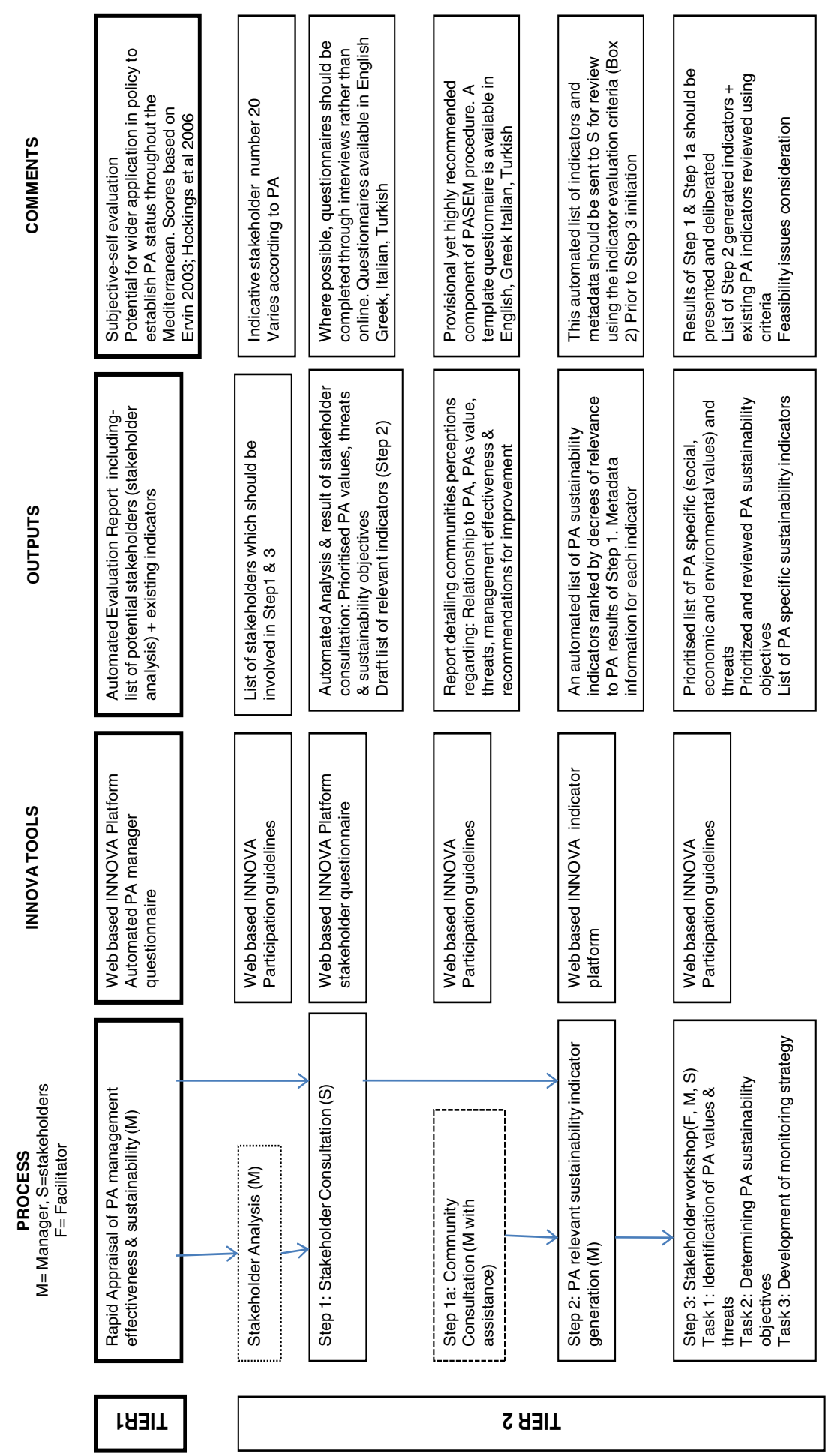

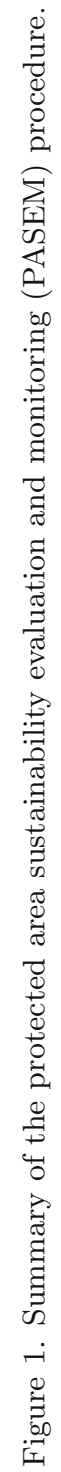


and justification of results obtained. Tier 2 is a procedure for the selection of PA specific sustainability indicators and for the participatory development of a monitoring strategy. Specifically, outputs from the INNOVA platform are:

- A management effectiveness evaluation report for the specific PA.

- A better understanding of the management and monitoring issues of the PA.

- A list of potential stakeholders to be contacted for the Tier 2 evaluation process, should Tier 2 be required.

- A list of potentially available data and indicators which could be used.

\subsection{Tier 1: Rapid appraisal of PA management effectiveness and sustainability}

Tier 1 consists of a fast simple assessment which enables PA managers to evaluate management effectiveness and sustainability. It is questionnaire based. A number of questions and embedded scoring have been obtained from Ervin (2003) and Hockings et al (2006). Additional questions have been incorporated to obtain information regarding the sustainability of the PA as well as participation, which are aimed at providing necessary input for the Tier 2 process (developing a sustainability monitoring strategy).

Based on the pilot trials, the rapid appraisal questionnaire takes approximately half a day of a manager's time to complete online. Following its completion the user is automatically provided with an evaluation report. This function has been included in order to minimize administration and encourage PA managers to conduct annual evaluations in order to regularly establish PA management progress. In some sections, the assessment is based on the manager's perception of the situation within the PA. Thus, PA managers should be honest and consider the evaluation as a self improvement opportunity, rather than a judgmental exercise.

Positive feedback was received from the six pilot studies of PA managers regarding Tier 1 application. However, managers noted some difficulty due to lack of existing data sources to answer all the questions. By conducting the appraisals, managers understood what further actions were required to improve management and develop a monitoring strategy.

\subsection{Tier 2: PA sustainability monitoring strategy development procedure}

Tier 2 consists of a three-step procedure (figure 1) and requires a stakeholder analysis prior to initiation as it is participatory - involving workshops.
It is designed with flexibility, such as nonmandatory components, to assist PA managers who do not have necessary resources for large expensive monitoring strategies or extensive participation processes.

The Tier 2 process is designed to be led by the PA manager, thus promoting incorporation of outcomes into existing decision making processes. The assistance of a trained facilitator to carry out and organize the participation activities is strongly encouraged. The time required to complete the full process depended on the size of the PA (e.g., the number of community questionnaires to be completed in Step 1a) and the number of relevant stakeholders to be consulted in Step 1. Using the INNOVA platform reduced the time required for data analysis and reporting. Participation data collection timing varied. In the pilot studies, the process of sustainability monitoring strategy development took, on average, 3 months to complete. However, it should be noted that $70 \%$ of the time and effort was allocated to the community consultation which is an optional component of the process (see section 4.2.2a).

\subsubsection{Stakeholder analysis}

Participation is an essential component of the PASEM procedure; it is the stakeholders who define the sustainability values of the PA and provide their invaluable knowledge on important issues. Specifically in Tier 2, stakeholders are required to:

- complete a stakeholder questionnaire to identify the sustainability perceptions (values, threats, sustainability objectives; Step 1);

- attend a 1 day workshop to agree a specific set of indicators and monitoring strategy (Step 3).

It is imperative that appropriate stakeholders are identified and encouraged to take part. To facilitate stakeholder consultation, a stakeholder analysis procedure was developed and implemented as part of the pilot studies. Such a procedure supports PA managers who lack experience in participation and any tendency to involve the common suspects. A guidance document is available as part of INNOVA platform. A guideline number of 12 to 20 participants in Tier 2 of PASEM procedure is proposed, though the ideal number of participants is case specific. Indeed, carrying out the process may reveal more stakeholders which should be involved.

\subsubsection{Step 1: PA stakeholder consultation}

The aim of Tier 2 Step 1 (figure 1) is to identify stakeholders and obtain their views using the 
stakeholder questionnaires and workshops, regarding:

- PA values,

- threats to the PA,

- priority objectives for sustainable management of the PA,

- satisfaction with existing participation and information provision processes,

- recommendations on other stakeholders to engage.

Step 1 stakeholder questionnaires are completed online using the INNOVA platform and analysis is conducted to determine:

- important environmental social and economic values of the PA to protect and monitored (based on table 2);

- the five most important threats facing the PA (based on frequency counts and table 4),

- the priority environmental, social, economic and governance objectives for a sustainable (based on table 4).

The results are subsequently automatically processed by the INNOVA indicator platform (Step 2) to generate a list of indicators relevant to the identified priority values, threats and objectives. The prioritization analysis occurs between values and objectives within a sustainability dimension (e.g., environmental objectives), not across the sustainable dimensions. These results are compiled into a report and disseminated to all contributing stakeholders for review.

\subsection{2a Step 1a: Community consultation}

Past trends in PA management consisted of attempts to exclude local communities from decision making, and superimpose resource exploitation restrictions (Borrini-Feyerabend et al 2004). However, Hockings et al (2006) asserts that in order for PA to achieve their goals, local communities should be involved in their designing, management and monitoring. Furthermore, underestimating local perceptions can lead to conflicts and misunderstandings between agencies and the local population, a major cause of failure in the management of PA (Borrini-Feyerabend 1996). Thus an essential component of the PASEM is consideration of local communities needs, aspirations and attitudes.

Community participation is not an easy task and needs to be planned (Collier 2002). Communities have many competing demands for their time; raising the question 'to what extent should the local community be expected to participate in developing a monitoring strategy for a PA?' Furthermore, 'to what lengths should one go to try to involve them?', especially, when participation takes time and money. IEMA (2002) describe a range of participation methods, ranging in levels of involvement, their advantages and disadvantages. The PASEM adopts a pragmatic approach and provides guidance for community participation within the INNOVA platform.

Specifically, PASEM recommends the use of household surveys oriented on perceived values, goals, threats of the PA, and participation to date. As a minimum, the questionnaire should cover:

- Demographics and relationship of household to PA,

- Satisfaction to PA information provision and participation,

- Perceptions of PA management effectiveness,

- Identification of PA main problems and recommendations for improvement.

The community survey provides useful information for the development of management strategies and indicators. A template questionnaire is available on the INNOVA platform. Step 2 informs Step 3; i.e., selection of community relevant sustainability indicators. The results from the community survey are presented at the stakeholder workshop (section 4.2.3) to compare whether community views are compatible to those of the stakeholders present.

In the pilot studies the results of the community survey were presented in a report and disseminated to all stakeholders. The Greek pilot, published in the local press, generated a lot of interest in the process. However, a survey may not always be the most appropriate way to collect information; as in the Egyptian pilot. Here, informal interviews with family heads were employed as this was considered a culturally more acceptable approach. In addition, it is recognized that community surveys do not consist of two-way communication and thus the use of a variety of methods, including open days and local publicity is encouraged (Sanoff 2000).

The validity of stakeholder workshop as community consultation was questioned during the pilot studies as only community representatives can be involved. The Greek pilot study highlighted a significant difference between the views of the PA manager, local communities and other stakeholders, which led to the decision to give more emphasis to community engagement in future PA management activities. Thus, community consultation is recommended in Step 3 of the process. In all but one of the pilot studies, stakeholders and the PA managers expressed significant interest in the community survey results. In the Italian pilot 
PA, the majority of the community consisted of holiday home residents, considered by stakeholders as foreigners, with whom tensions had arisen regarding rights in PA management. Overall, community consultation is presented as an optional yet highly recommended component of the PASEM process.

\subsubsection{Step 2. Using the INNOVA platform to generate an initial set of $P A$ sustainability indicators}

The INNOVA platform incorporates a large database of sustainability indicators obtained from various sources and existing international databases. Each indicator has been characterized using descriptive and classification metadata (Pace and Di Terlizzi 2008). This characterization is inextricably linked to the stakeholder questionnaire to enable automatic selection of PA specific indicators, provided to the user in the form of a report together with instructions for review. Indicator evaluation criteria were also developed (based on Pediaditi et al 2007). The results of the stakeholder consultation and community consultation (Tier 2, steps 1 and $1 \mathrm{a}$ ) and the list of generated indicators (Step 2) are disseminated to stakeholders for their input prior to subsequent workshops as it ensures transparency and provides opportunity for detailed input.

One of the advantages of the INNOVA platform is that it is an open system, which allows its users to add relevant indicators and fill in their metadata files. This results in a continually updated and growing indicator database for Mediterranean PA, something which is currently unavailable (Pace and Di Terlizzi 2008). We therefore invite scientists, involved in indicator development for environmental conservation and management, to use the platform and enter their indicators and information on their appropriate application, thus making them available to protected area managers.

\subsubsection{Step 3: Stakeholder workshop for the identification of a final set of indicators and a monitoring strategy}

The final step - Step 3 (figure 1), consists of a one day workshop with stakeholders and the PA manager. During the workshop, stakeholders must complete three tasks using interactive methods to determine the PAs:

- main threats and values (Task 1)

- priority sustainability objectives (Task 2)

- sustainability indicators and monitoring strategy (Task 3)
The workshop requires focused activities, in a limited period of time, by a range of stakeholders with different backgrounds and vested interests. Therefore, in order that the workshop is effective and fruitful, it is imperative that it is coordinated by a trained facilitator. The facilitation structure described below is proposed having been trialed and evaluated as effective in six pilot studies.

\subsection{4a Step 3, Task 1: Identifying main threats to and values of PA}

For Task 1, stakeholders should be split up into groups of between three and six; each group scribes the priority threats and the main values of the PA on 'post-it'TM notes, separately for environmental, economic and socio-cultural values. The postit $^{\mathrm{TM}}$ notes should be placed by individuals after group discussions into themes on posters. A combined carousel and metaplan facilitation technique is proposed (Environment Council 2002) in order to enable all participants to view what other participants have stated and to add to them. Comments are later reported by the facilitator. At this point, the results of the community consultation and stakeholder consultation (Step 1) are presented and discussed, considering differences presented by the community to those of the group. Agreement should be reached on the main threats and values. The pilot studies experienced extensive deliberation between different stakeholders and new perspectives being shared, such as overperceived differences in threats and values, emphasizing the importance of Step 1a.

\subsection{4b Step 3 Task 2: Agreeing on sustainability objectives for the PA}

In Task 2, stakeholders prioritize generic sustainability objectives of table 4 , in light of the Task 1 results. Posters with economic, social, environmental and governance sustainability objectives should be presented and participants should be provided with sticky dots to state their priorities. Participants must prioritize between objectives within each objective category to reduce the opportunity for tradeoffs between the pillars of sustainability, enabling a holistic approach (Owens and Cowel 2002).

Participants then review and refine the prioritized objectives for PA context specificity. Group revised objectives should be presented and, using nominal group technique (Environment Council 2002), a consensus reached of eight site specific objectives, two reflecting each sustainability dimension. These objectives are carried forward to Task 3. 


\subsection{4c Step 3, Task 3: Agreeing on a manageable} set of indicators and monitoring strategy

For the final task, workshop stakeholders are asked to deliberate on the proposed indicators produced by the INNOVA platform and using the indicator evaluation criteria in combination with the prioritized list of PA threats, values and sustainability objectives (stakeholder workshop, Task 1 and Task 2) agree on a final set of 24 indicators and a monitoring strategy. The indicator evaluation criteria, examined issues of relevance, availability, cost effectiveness as well as posed methodological questions such as data collection timing appropriateness, etc. The proposed facilitation method enabled all workshop participants to propose and discuss practical aspects in applying the indicators. Pilot study observations revealed that stakeholders, although not indicator experts, had grounded knowledge regarding existing data and a realistic view of the practical issues of data collection and analysis. Task 3 results in prescribed indicators with procedural issues addressed, thereby increasing their practicality, feasibility and utility. Outcomes of the Step 3 workshop are written up in a report and disseminated to stakeholders and the PA manager for implementation.

An observation from the pilot studies was that workshop proposals for implementing monitoring varied greatly. This is not unexpected given the differing nature of the pilot PA (table 1). Other generic conclusions include: PAs which did not yet have a formal management body or plan proposed more informal approaches, such as willingness to increase collaboration between themselves and share data, as well as the need to initiate procedures to develop more formalized management structures. For one pilot study, a proposal to incorporate PASEM outcomes into the management plan, which was under revision at the time, was adopted.

\section{Evaluating the PASEM and its future prospects}

The six pilot studies were essential in valuating the PASEM procedures' effectiveness. Questionnaires and interviews were conducted with all pilot participants including workshop non-participant observers to document experience of utilizing the PASEM. Overall, participants were very positive about the PASEM procedure with some PA managers proposing to apply it to other PAs in their jurisdiction. The main common benefits perceived by all participants was that of improved communication between stakeholders, acknowledgement of different perspectives and a greater understanding of PA management sustainability.

Very positive feedback was obtained in respect of the PASEMs' stakeholder and community participation procedures. However, the project context must be considered. Both stakeholder interviews (Step 1) and community surveys (Step 1a) were funded through the INNOVA project. PA pilot managers pointed out that existing budget would not have allowed for such extensive consultation. Participants advocate wider adoption of the PASEM procedure, yet saw this happening only through policy and legislation (EU or National) or in the context of externally funded projects.

The value of the INNOVA platform was highlighted by PA managers who commented on the opportunities presented, mainly the automated management effectiveness evaluation report production (Tier 1) and indicator selection (Step 2).

Reflecting on the applicability of the PASEM, the widespread perception that the procedure was useful was very encouraging, given the differing institutional, ecological, economical and social contexts of the pilot studies. The decision to allow methodological flexibility guidance rather than strict top down indicators proved invaluable.

\section{Conclusions}

A process for the functional relevant use of existing indicators to assess the sustainability of PA throughout the Mediterranean has been presented. A review of existing PA tools and procedures indicated significant amount of literature on evaluation, in particular in management effectiveness; but less so for sustainability outcome evaluation. Furthermore, a procedure for monitoring and evaluating PA sustainability in the Mediterranean region did not exist. Evidence on the adoption of existing tools was limited and attributed in part to the lack of consideration of user needs prior to procedure development. The PASEM was devised as a procedure to be context specific, practical, relevant to management and governance procedures, holistic and participatory in nature. The six pilot trials indicated the potential for the PASEMs wider application, however its voluntary nature will invariably limit its wider uptake. Therefore, the voluntary use by PA managers is promoted through this paper, until a stronger political will and policy push for a procedure and DSS such as the PASEM is proposed, taking into account the various international, and regional commitments made by Mediterranean states to halt the loss of biodiversity and make progress towards sustainable development. 


\section{Acknowledgements}

This research was funded under INTERREG III B Programme 'Archimed' A.1.222 INNOVA Project. The authors would like to acknowledge the contribution and input of the partners, protected area authorities, stakeholders and local communities. Special thanks to the University of Bari, the Polytechnic of Bari, Apulian Ministry of Environment, University of Lecce, Maltese Ministry of Rural Affairs and Environment, University of Malta, Agricultural Research Institute of Cyprus, Prefecture of Chania, Egyptian Desert Research Center, Palestinian Ministry of Agriculture, Palestinian National Authority, and Al Quads University.

\section{References}

Bell S and Morse S 2003 Measuring Sustainability, Learning from Doing; Earthscan, London.

Benoit G and Comeau A 2005 A Sustainable Future for the Mediterranean: The Blue Plan's Environment and Development Outlook; Earthscan, London.

Bertzky M and Stoll-Kleemann S 2009 Multi-level discrepancies with sharing data on protected areas: What we have and what we need for the global village; J. Environ. Manag. 90 8-24.

Bladt J, Strange N, Abildtrup J, Svenning J C and Skov F 2009 Conservation efficiency of geopolitical coordination in the EU; Journal for Nature Conservation 17(2) 72-86.

Bogliotti C 2006 A conceptual model to frame goals of sustainable development; Int. J. Sustain. Dev. Plann. 1(4) 381-398.

Borrini-Feyerabend G 1996 Collaborative management of Protected Areas: Tailoring the approach to the context; IUCN Social Policy Group, Switzerland.

Borrini-Feyerabend G, Kothari A and Oviedo G 2004 Indigenous and Local Communities and Protected Areas: Towards Equity and Enhanced Conservation; IUCN, Gland, Switzerland and Cambridge, UK.

Collier C 2002 Community Stakeholder Involvement; CIRI-6349A, September, www.safegrounds.com/other_ guidance.htm (accessed 19.12.2008).

Davidson E J 2005 Evaluation methodology basics, the nuts and bolts of sound evaluation; Sage, London.

Delbaere B 2006 European policy review - assessing policy impacts on biodiversity; J. Nat. Conserv. 14(2) 129-130.

Environment Council 2002 Dialogue for sustainability: Facilitation skills and principles; Environmental Council $\mathrm{C} 1 / \mathrm{V} 1$, London.

Ervin J 2003 WWF: Rapid Assessment and Prioritization of Protected Area Management (RAPPAM) Methodology; WWF, Gland, Switzerland.

Gross N 2006 Beyond expertise: Ecological science and the making of robust restoration strategies; J. Nat. Conserv. 14(3-4) 172-179.

Hardi P and Zdan T 1997 Assessing Sustainable Development: Principles in Practice; IISD, Canada.

Hockings M 2003 Systems for assessing the effectiveness of management in protected areas; Bioscience $\mathbf{5 3 ( 9 )}$ 823-832.

Hockings M, Stolton S and Dudley N 2004 Management effectiveness: Assessing management of protected areas? J. Environ. Pol. Plann. 6(2) 157-174.
Hockings M, Stolton S, Leverington F, Dudley N and Courrau J 2006 Evaluating effectiveness: A framework for assessing management effectiveness of protected areas; 2nd edn, IUCN, Gland, Switzerland.

IEMA (Institute of Environmental Management and Assessment) 2002 Perspectives, guidelines on participation in environmental decision making; IEMA, Lincoln.

IUCN 1994 Guidelines for Protected Areas Management Categories; IUCN, Cambridge, UK and Gland, Switzerland.

Mitchell G 1996 Problems and fundamentals of sustainable development indicators; Sustainable Development 4 1-11.

Olson D M and Dinerstein E 1998 The Global 200: A representation approach to conserving the Earth's most biologically valuable ecoregions; Conserv. Biol. 12(8) 502-515.

Owens S and Cowel R 2002 Land and limits: Interpreting sustainability in the planning process; Routledge, London.

Pace F and Di Terlizzi B (eds) 2008 Planning and Sustainable Management of Coastal Zones and High Environmental Value Areas. Final Networks' Meeting and Seminar Proceedings, Bari, Italy, 17-18 December 2007, IAM Bari, Italy.

Patton M Q 1997 Utilization-Focused Evaluation: The New Century Text; 3rd edn, Thousand Oaks, Sage, London.

Pediaditi K, Wehrmeyer W and Burningham K 2007 Evaluating the sustainability of Brownfield redevelopment projects; In: Sustainable Brownfield Regeneration, livable places from problem spaces (eds) Dixon T, Raco M, Cartney P and Lerner D (Oxford: Blackwell Publishing) pp. 141-163.

Posavac E J and Carey R G 2007 Program Evaluations: Methods and Case Studies, 7th edn, Prentice Hall, New Jersey.

Rotheroo N, Mohon S and King B 1997 Do the indicators of sustainable development produced by the UK government and indicators developed within various local agenda 21 initiatives have common characteristics from which core indicators can be developed?, Proceedings International Development Res. Conf., Manchester, JRP Environment.

Rydin Y, Holman Y, Hands V and Sommer F 2003 Incorporating sustainable development concerns into an urban regeneration project: How politics can defeat procedures; J. Environ. Plann. Manag. 46(4) 545-562.

Sanoff H 2000 Community Participation Methods in Design and Planning; John Wiley and Sons, USA.

Scriven M 1991 Evaluation thesaurus; 4th edn, Sage, Newbury Park: CA.

Shalock R L 2001 Outcome-based Evaluation; 2nd edn, Kluwer Academic Press/Plenum, London.

Stufflebeam D L and Shinkfield A J 2007 Evaluation theory, models and applications; Jossey-Bass, CA.

Sutherland W J, Pullin A S, Dolman P M and Knight T M 2004 The need for evidence-based conservation; Trends in Ecology and Evolution 19 305-308.

Sutherland W J, Armstrong-Brown S, Armsworth P R, Brereton T, Brickland J, Campbell C D, Chamberlain D E, Cooke A I, Dulvy N K, Dusic N R, Fitton M, Freckleton R P, Godfray H C, Grout N, Harvey H J, Hedley C, Hopkins J J, Kift N B, Kirby J, Kunin W E, MacDonald D W, Markee B, Naura M, Neale A R, Oliver T, Osborn D, Pullin A S, Shardlow M E A, Showler D A, Smith P L, Smithers R J, Solandt J-L, Spencer J, Spray C J, Thomas C D, Thompson J, Webb S E, Yalden D W and Watkinson A R 2006 The identification of one hundred ecological questions of high policy relevance in the UK; J. Appl. Ecol. 43 617-627.

Thomas L and Middleton J 2003 Guidelines for Management Planning of Protected Areas; IUCN Gland, Switzerland and Cambridge, UK. 
Thorsell J W 1982 Evaluating effective management in protected areas: An application to Arusha National Park; Tanzamia, IUCN Commission on National Parks and Protected Areas, Gland, Switzerland.
UNEP 1996 Protocol Concerning Specially Protected Areas and Biological Diversity in the Mediterranean; Monaco.

Ukaga O 2001 Participatory valuation of sustainable development; Greener Management International 36 27-36.

MS received 8 November 2010; revised 29 March 2011; accepted 2 April 2011 